\title{
Morphology, Structural, Thermal, and Tensile Properties of Bamboo Microcrystalline Cellulose/Poly(Lactic Acid)/Poly(Butylene Succinate) Composites
}

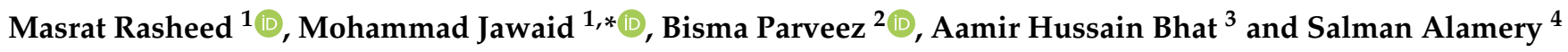 \\ 1 Laboratory of Biocomposite Technology, Institute of Tropical Forestry and Forest Products (INTROP), \\ Universiti Putra Malaysia, Serdang 43400, Selangor, Malaysia; masuqayyuum@gmail.com \\ 2 Kulliyan of Engineering (KOE), Islamic International University Malaysia, \\ Gombak 53100, Kuala Lumpur, Malaysia; mirbisma5555@gmail.com \\ 3 Department of Applied Sciences, Higher College of Technology, University of Technology and Applied \\ Sciences, Al-Khuwair, Muscat 133, Oman; bhataamir@gmail.com \\ 4 Department of Biochemistry, College of Science, King Saud University, P.O. Box 22452, \\ Riyadh 11451, Saudi Arabia; salamery@ksu.edu.sa \\ * Correspondence: jawaid@upm.edu.my; Tel.: +60-3-97696960
}

Citation: Rasheed, M.; Jawaid, M.; Parveez, B.; Hussain Bhat, A.; Alamery, S. Morphology, Structural, Thermal, and Tensile Properties of Bamboo Microcrystalline Cellulose/Poly(Lactic Acid)/Poly (Butylene Succinate) Composites. Polymers 2021, 13, 465. https://doi. org/10.3390/polym13030465

Academic Editor: Maya Jacob John Received: 26 December 2020

Accepted: 19 January 2021

Published: 1 February 2021

Publisher's Note: MDPI stays neutral with regard to jurisdictional claims in published maps and institutional affiliations.

Copyright: (c) 2021 by the authors. Licensee MDPI, Basel, Switzerland. This article is an open access article distributed under the terms and conditions of the Creative Commons Attribution (CC BY) license (https:/ / creativecommons.org/licenses/by/ $4.0 /)$.

\begin{abstract}
The present study aims to develop a biodegradable polymer blend that is environmentally friendly and has comparable tensile and thermal properties with synthetic plastics. In this work, microcrystalline cellulose (MCC) extracted from bamboo-chips-reinforced poly (lactic acid) (PLA) and poly (butylene succinate) (PBS) blend composites were fabricated by melt-mixing at $180{ }^{\circ} \mathrm{C}$ and then hot pressing at $180^{\circ} \mathrm{C}$. PBS and $\mathrm{MCC}(0.5,1,1.5 \mathrm{wt} \%)$ were added to improve the brittle nature of PLA. Field emission scanning electron microscopy (FESEM), scanning electron microscopy (SEM), X-ray diffraction (XRD), Fourier transform infrared spectroscope (FTIR), thermogravimetric analysis (TGA), differential thermogravimetry (DTG), differential scanning calorimetry (DSC)), and universal testing machine were used to analyze morphology, crystallinity, physiochemical, thermal, and tensile properties, respectively. The thermal stability of the PLA-PBS blends enhanced on addition of MCC up to $1 \mathrm{wt} \%$ due to their uniform dispersion in the polymer matrix. Tensile properties declined on addition of PBS and increased with MCC above (0.5 wt \%) however except elongation at break increased on addition of PBS then decreased insignificantly on addition of MCC. Thus, PBS and MCC addition in PLA matrix decreases the brittleness, making it a potential contender that could be considered to replace plastics that are used for food packaging.
\end{abstract}

Keywords: poly(lactic acid); microcrystalline cellulose; poly(butylene succinate); scanning electron microscopy; tensile properties

\section{Introduction}

In current years, due to the higher usage of plastics, their disposals cause environmental pollution that is of great concern. This problem can be solved by the usage of biodegradable materials which are easily disposed due to their microbial action, as a replacement to the synthetic polymers. PLA, PBS, and MCC based composites can fulfil the requirement of replacing commodity synthetic polymers. PLA and PBS are biodegradable polyesters with great degradability and mechanical properties. Since PLA behold amazing thermal, mechanical, and biodegradable properties, it holds a great potential usage in polymer-based applications [1]. In contrast, properties such as flexural properties, impact strength, gas permeability, melt viscosity required for processing, heat distortion temperature (HDT), etc. are not adequate for packaging applications [2]. Additionally, brittleness and higher cost of PLA restricts their potential for commercial usage.

Therefore, combining PLA with other appropriate biodegradable polymer with comparatively better melt processability, flexural properties, and excellent impact strength, 
can not only improve its properties but also reduces overall material cost. PBA is mostly preferred as it possesses the required properties. Thus, to enhance the properties and minimize the cost of production, numerous works on PLA blended with various biodegradable polymers were executed [3-5]. Bhatia et al. [6] fabricated a blend of PLA and PBS and observed that the blend up to $80 / 20 \mathrm{wt} \%$ (PLA-PBS) composition was partial miscibility. The brittle nature of PLA was reduced by the PBS; therefore, it can be considered as a potential material as a replacement of plastics for packaging applications. However, there was reduction of tensile strength, tensile modulus, and percentage elongation at break as PBS content increased. Liu et al. [7] repaired a blend of PLA and poly (ethylene/butylene succinate) or Binolle and observed that the addition of Bionolle resulted into crystallization of PLA and a small increment in the strain at break, however, there was reduction of ultimate tensile strength and modulus.

Also, Yokohara \& Yamaguchi [8] examined the structure and various properties of PLA blended with fibrous PBS and spherical particles of PBS. PBS particle led to nucleation of PLA results into an increase in the crystallinity and it was further enhanced by the heating process. Homklin and Hongsriphan [9] reported the effect of nucleating agents such as sodium benzoate and nano-sized calcium carbonate on mechanical strength and thermal stability of PLA-PBS blends and on filling these blends with the nucleating agents, their tensile strength, energy, and elongation at break reduced. This was because of increased PLA phase crystallinity and the occurrence of stress concentration in these blends.

Microcrystalline cellulose (MCC) is a natural source with added benefits-like low cost, abundance in availability, high strength to weight ratio, renewability, and low densitymakes it progressively a potential material as reinforcement for the fabrication of composites $[10,11]$. Although there are some challenges and further research are carried out to improve their functionalities in order to increase their applications in the materials [12]. PLA and PBS are synthetic polymers(polyesters) but MCC are the micro sized cellulose extracted mostly from plant fibers or other cellulosic waste via acid hydrolysis technique in order to eliminate their amorphous part [13-15]. All of the three biodegradable materials have been commercialized extensively for reduction of the number of plastics in found in the waste disposal. Even though being so beneficial they have got some limitations, low melt strength, brittleness, lower thermal stability, and lower strength that limits their application and their large-scale production [16-18]. However, their blends or composites may compensate their distinct shortcomings because it may lead to enhancement of properties of the developed composites.

Various researchers examined the effect of MCC on the performances of polymers composites [19,20]. Cao et al. [21] examined the effect of the content of a chain-extender on the microstructure and performance of PLA-PBS-MCC composites and observed with the incorporation of chain extender processability and strength of the composites were improved. A few researchers have previously investigated PLA-PBS-MCC composites but there is still a need to explore such composites that can in future replace plastics effectively and thus diminish the level of plastic wastes in waste disposal that otherwise lead to environmental pollution. As from the literature PLA-PBS-MCC composites are not yet studied extensively so far. In addition, these composites may also provide a new possibility of obtaining tailored and more desirable performance of biodegradable plastics, and further enhance their thermal stability and mechanical properties.

In this work, PLA-PBS-MCC composites were fabricated via the hot-pressing technique and the morphology, crystallinity, physiological, and mechanical properties and their thermal behavior were evaluated by carrying out FESEM, XRD, FTIR, tensile testing, TGA, and DSC analysis respectively. This work aims to improve our understanding and endorse the development of multi constituent materials with desirable properties and also explore the potential of MCC in packaging applications. 


\section{Experimentation}

\subsection{Materials}

Pellet form PLA (7001 IngeoTM of specific gravity 1.24) utilized in this study were obtained from Nature Works LCC, MN, USA. It has melting point of $154^{\circ} \mathrm{C}$ and hydrophobic in nature. PBS of density $1.26 \mathrm{~g} / \mathrm{cm}^{3}$ in pellet form were obtained from PTT public company limited in Bangkok, Thailand. It has a melting point of $95^{\circ} \mathrm{C}$. MCC were isolated from bamboo fiber through acid hydrolysis technique and further ultrasonicated to prevent agglomeration [22].

\subsection{Methods}

\subsubsection{Extraction of MCC from Bamboo Fiber}

Bamboo fiber was used as a source of MCC and were extracted from it by acid hydrolysis technique. The fiber was first bleached to obtain separate lignin and hemicellulose and pre-treated bamboo pulp then was hydrolyzed with sulphuric acid of concentration $85 \mathrm{wt} \%$ for $30 \mathrm{~min}$ and finally MCC were obtained. These were further vacuum oven dried at 80 for $24 \mathrm{~h}$ to get dispersed and high quality MCC. Thus, MCC of higher yield of $80 \%$ and crystallinity index of $82.6 \%$ were obtained [23].

\subsubsection{Fabricated of MCC Reinforced PLA/PBS Composites}

MCC, PBS, and PLA were initially oven-dried at a temperature of $60^{\circ} \mathrm{C}$ for $24 \mathrm{~h}$. Five compositions, as demonstrated in Table 1, were prepared using hot pressing technique. Initially the constituents of compositions were mixed by Brabender mixer (melt mixer) at the temperature of $180{ }^{\circ} \mathrm{C}$ for $15 \mathrm{~min}$ at $60 \mathrm{rpm}$. The mixture was then crushed in a crusher to get it in the form of pellets. Compressed sheets with the thickness of $0.12 \mathrm{~mm}$ were obtained by hot compression of these pellets in a hot press at the constant pressing pressure of $150 \mathrm{MPa}$ and the temperature of $180{ }^{\circ} \mathrm{C}$ for reheating time of $4 \mathrm{~min}$ and then pressing time of $3 \mathrm{~min}$ as shown in Table 2. The compressed sheets were then oven-dried for $24 \mathrm{~h}$ at a constant temperature of $50{ }^{\circ} \mathrm{C}$ and prior to testing stored in desiccator.

Table 1. Composition of PLA/PBS/MCC Composites

\begin{tabular}{ccccc}
\hline S.No & Composite & PLA (wt\%) & PBS (wt\%) & MCC \\
\hline 1. & M1 & 100 & 0 & 0 \\
2. & M2 & 80 & 20 & 0 \\
3. & M3 & 80 & 20 & 0.5 \\
4. & M4 & 80 & 20 & 1 \\
5. & M5 & 80 & 20 & 1.5 \\
\hline
\end{tabular}

Table 2. Fabrication Process Parameters.

\begin{tabular}{ccccc}
\hline \multirow{2}{*}{ Process } & $\begin{array}{c}\text { Temperature } \\
\left({ }^{\circ} \mathbf{C}\right)\end{array}$ & Pressure (MPa) & $\begin{array}{c}\text { Time } \\
(\mathbf{m i n})\end{array}$ & Speed (rpm) \\
\hline Melt mixing & 180 & - & 15 & 60 \\
Hot pressing & 180 & 150 & 3 & - \\
\hline
\end{tabular}

\subsection{Characterization and Testing}

\subsubsection{Field Emission Scanning Electron Microscopy (FESEM)}

The surface morphologies of composite films were acquired at 10-20 kV (accelerating voltage) using FESEM (JEOL JSM-7000F) from Tokyo, Japan. The films were first coated before examination to avoid electrostatic charging. 


\subsubsection{Scanning Electron Microscopy (SEM)}

The fractured surface of composite films was analyzed by SEM (Jeol, JSM 5410LV) (Hitachi Model S-3400N) from Tokyo, Japan. Specimens were tensile fracture. The samples were fixed to the stub by means of carbon tape and prior to inspection sputter-coating of gold was applied to the fractured surface to avoid electrostatic charging.

\subsubsection{X-ray Diffraction (XRD)}

XRD analysis of composites was executed to find the crystallinity of composite films at an angular incidence of $5^{\circ}$ to $40^{\circ}$ using Ni-filtered $\mathrm{Cu}$ K-alpha radiation by SHIMADZU XRD-6000 X-ray diffractometer, from Tokyo Japan.

\subsubsection{Fourier Transform Infrared Spectroscope (FTIR)}

The functional group analysis of each sample was examined at $4 \mathrm{~cm}^{-1}$ (resolution) by 32 scans using an imaging microscope (Perkin Elmer 1600 Infrared spectrometer, MA, USA) within a frequency ranging from 500 to $4000 \mathrm{~cm}^{-1}$

\subsubsection{Thermal Characterization}

Thermal stability of the composite films was estimated by carrying out TGA (Perkinelmer TGA7, MA, USA) at a heat rate of $10^{\circ} \mathrm{C} / \mathrm{min}$ in range of $10-600^{\circ} \mathrm{C}$ in a nitrogen atmosphere. Samples of around $10 \mathrm{mg}$ were cut from the films and the change in their weight ratio with respect to temperature was recorded. Thermal analysis was executed using DSC (Perkin-Elmer DSC7, MA, USA) where aluminum pan that was empty was taken as a reference. Samples of weight around 3-5 $\mathrm{mg}$ were placed in a pan and a temperature scan was done at a heat rate of $10^{\circ} \mathrm{C} / \mathrm{min}$ from $0-200{ }^{\circ} \mathrm{C}$ under a nitrogen atmosphere. From the thermogram attained, glass transition temperature $\left(\mathrm{T}_{\mathrm{g}}\right)$, crystallisation temperature $\left(\mathrm{T}_{\mathrm{c}}\right)$, and melting temperature $\left(\mathrm{T}_{\mathrm{m}}\right)$ of the composite films were obtained.

\subsubsection{Tensile Properties}

Tensile properties were measured as per ASTM Standard Method (D638-14 (2014)) via (Lloyds LRX) Universal Testing Machine. Tensile testing was executed using samples of size $(10 \times 100 \mathrm{~mm})$ cut from the composite films, at $50 \mathrm{~mm}$ (initial grip separation) and $10 \mathrm{~mm} / \mathrm{min}$ (crosshead speed). Ten samples of each composition were dried at $50{ }^{\circ} \mathrm{C}$ for $24 \mathrm{~min}$ a conventional oven prior testing. The tensile strength and modulus properties, and elongation at break were acquired from tensile testing.

\section{Results and Discussions}

\subsection{FESEM}

The surface morphology of PLA(M1), PLA-PBS(M2), and PLA-PBS-MCC (M3, M4 and M5) composites was performed as illustrated in Figure 1. PLA composite demonstrated a smoother surface, due to the poor plastic deformation [24] as evident from Figure 1a, while the homogeneously distributed PBS phase exists in all PLA-PBS blends showing the compatibility of the PLA-PBS blends [25]. The addition of PBS up to $20 \mathrm{wt} \%$ better compatibility can possibly be attained [1]. It can be clearly seen from Figure 1c-e, MCC was dispersed throughout PLA matrix as well as embedded within PLA matrix because of its smaller size (micro-sized) as shown in Figure $1 \mathrm{f}-\mathrm{h}$. By adding MCC and increasing the MCC content in the PLA-PBS composite, the dispersed phase of MCC becomes clearer due to lower dispersion in PLA-PBS matrix [26] and with increasing MCC content the surface topography becomes rougher, as shown in Figure 1c-e. Moreover, MCC in previous works has proved to enhances the interaction at the interfaces of the PLA and PBS blend [27,28]. 

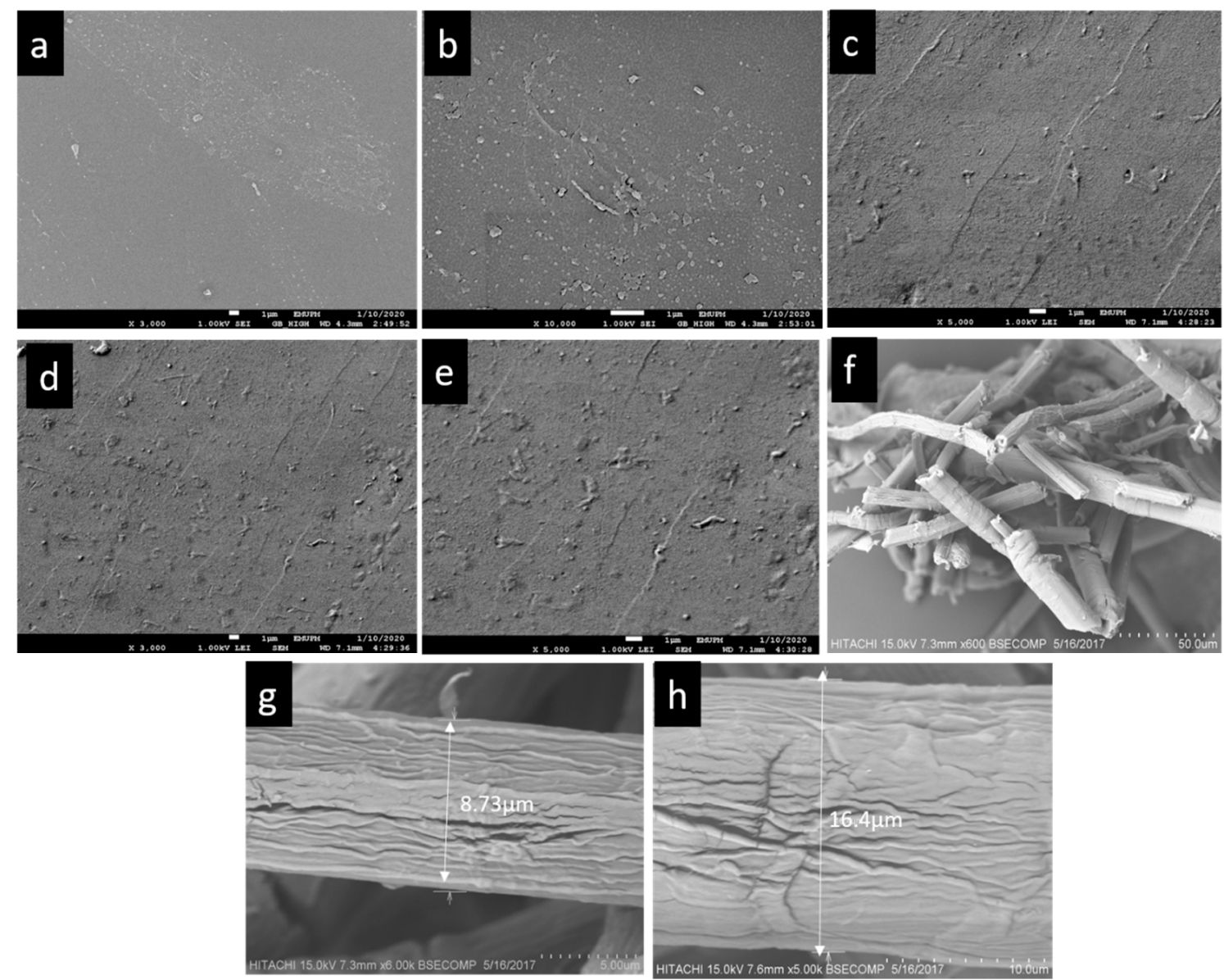

Figure 1. FESEM images of composite films (a) M1, (b) M2, (c) M3, (d) M4, (e) M5, (f,g,h) SEM images of MCC.

\subsection{Thermal Properties}

The thermal decomposition temperature of a polymer composite can be determined by its thermal degradation behavior. TGA was executed to examine the influence of PBS and MCC's on the thermal stability of PLA matrix composite films. The thermal stability of the composite films given by various parameters such as maximum degradation $\left(\mathrm{T}_{\max }\right)$, initial degradation $\left(\mathrm{T}_{\mathrm{i}}\right)$, temperature at $50 \%$ weight-loss $(\mathrm{T} 50 \%)$, and final degradation $\left(\mathrm{T}_{\mathrm{f}}\right)$ temperatures are evaluated using TGA. Figure 2 showing TGA curves of composites with varying percentages of MCCs. All the composites exhibited degradation processes in a single step, and the parameters of their thermal stability are given in Table 3. The PLA composites exhibited relatively lower thermal decomposition temperature in comparison to PLA-PBS and PLA-PBS-MCC composites. With addition of PBS the thermal stability of PLA-PBS blend increases. The $\mathrm{T}_{\max }, \mathrm{T}_{\mathrm{i}}, \mathrm{T} 50 \%$, and $\mathrm{T}_{\mathrm{f}}$, all increased on addition of up to $1 \mathrm{wt} \%$ MCC also similar behavior was reported by other researchers [21], then on further addition their values decrease as shown in Table 3. Even though MCC has low thermal stability when comparison with both PLA and PBS, still the char residue of MCC is expected to hinder the combustible gases to pass and diffuse into polymer matrix. Certainly, coke formed by decomposed MCC as earlier revealed to be uniformly distributed to the inside and surface of PLA-PBS-MCC composites, that efficiently impeded the discharge of decomposition products of PLA-PBS blends. Similar effect was observed for PLA-PBS-MCC blend [29] and polypropylene (PP)/MCC composites, where MCC effectively hindered the release of decomposition products of the polymers $[17,30]$. As evident from Table 3, PLA was found to have least residue which increased with the addition of PBS and MCC, due to their lower thermal stabilities as compared to PLA. 

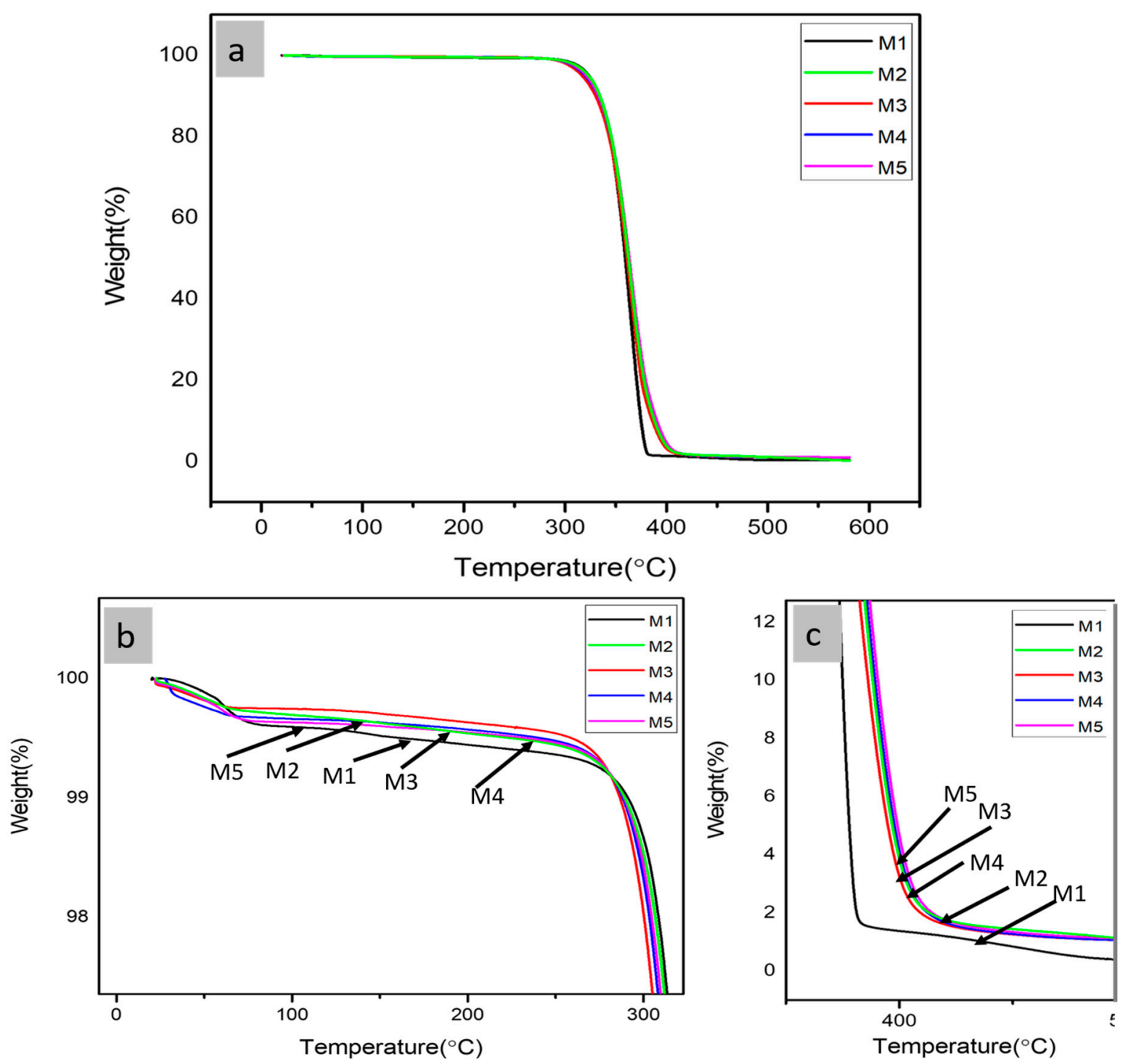

Figure 2. (a) TGA curves, (b) zoomed initial decomposition curves, (c) zoomed final decomposition curves of PLA-PBS-MCC composite films.

Table 3. TGA results of PLA/PBS/MCC composite films

\begin{tabular}{|c|c|c|c|c|c|c|c|c|}
\hline Samples & $\begin{array}{l}\mathrm{Ti}^{\mathrm{a}} \\
\left({ }^{\circ} \mathrm{C}\right)\end{array}$ & $\begin{array}{c}\mathrm{T} 50^{\mathrm{b} \%} \% \\
\left({ }^{\circ} \mathrm{C}\right)\end{array}$ & $\underset{\left({ }^{\circ} \mathrm{C}\right)}{\operatorname{Tmax}}$ & $\begin{array}{l}\text { Tf }{ }^{d} \\
\left({ }^{\circ} \mathrm{C}\right)\end{array}$ & $\begin{array}{l}\mathrm{Wi}^{\mathrm{e}} \\
\left({ }^{\circ} \mathrm{C}\right)\end{array}$ & $\begin{array}{c}\text { Wmax } \\
(\%)\end{array}$ & $\begin{array}{c}\text { Wfinal } \mathrm{g} \\
(\%)\end{array}$ & $\begin{array}{c}\text { Wresidue } \\
(\%)\end{array}$ \\
\hline M1 & 284.81 & 359.42 & 365.24 & 386.09 & 98.9 & 27.57 & 1.698 & 0.372 \\
\hline M2 & 286.66 & 361.197 & 365.72 & 416.72 & 98.95 & 22.76 & 2.131 & 1.044 \\
\hline M3 & 288.12 & 362.96 & 365.10 & 417.74 & 97.65 & 22.04 & 2.221 & 1.046 \\
\hline M4 & 289.22 & 363.11 & 366.50 & 419.65 & 96.43 & 21.65 & 2.163 & 1.064 \\
\hline M5 & 289.45 & 362.48 & 366.72 & 420.67 & 95.88 & 21.21 & 2.056 & 1.099 \\
\hline
\end{tabular}

${ }^{a}$ TGA; initial degradation temperature, ${ }^{b}$ TGA;50\% degradation temperature, ${ }^{c}$ DTG; peak temperature, ${ }^{d}$ TGA; final degradation temperature, ${ }^{\mathrm{e}}$ TGA: initial weight loss, ${ }^{\mathrm{f}}$ DTG maximum weight loss, ${ }^{\mathrm{g}}$ TGA; final weight loss, ${ }^{\mathrm{h}}$ TGA char residue weight.

DTG curves determine the loss of weight and the definite temperature at which material decomposition takes place. The thermal analysis of PLA, PLA-PBS, and PLA-PBS-MCC blend with varying percentages of MCC as evident from the Figure 3a,b. The thermal degradation temperatures increased, and thereby the thermal stability of composites increased as shown in Figure 3. It was found that M1, M2, M3, M4, and M5 displayed single step degradation as evident from Figure 3 . From Table $3, W_{\max }$ decreases with the 
addition of PBS then on addition of MCC it further reduces insignificantly, thus exhibiting improvement of thermal stability with PBS and MCC inclusion in PLA composites.
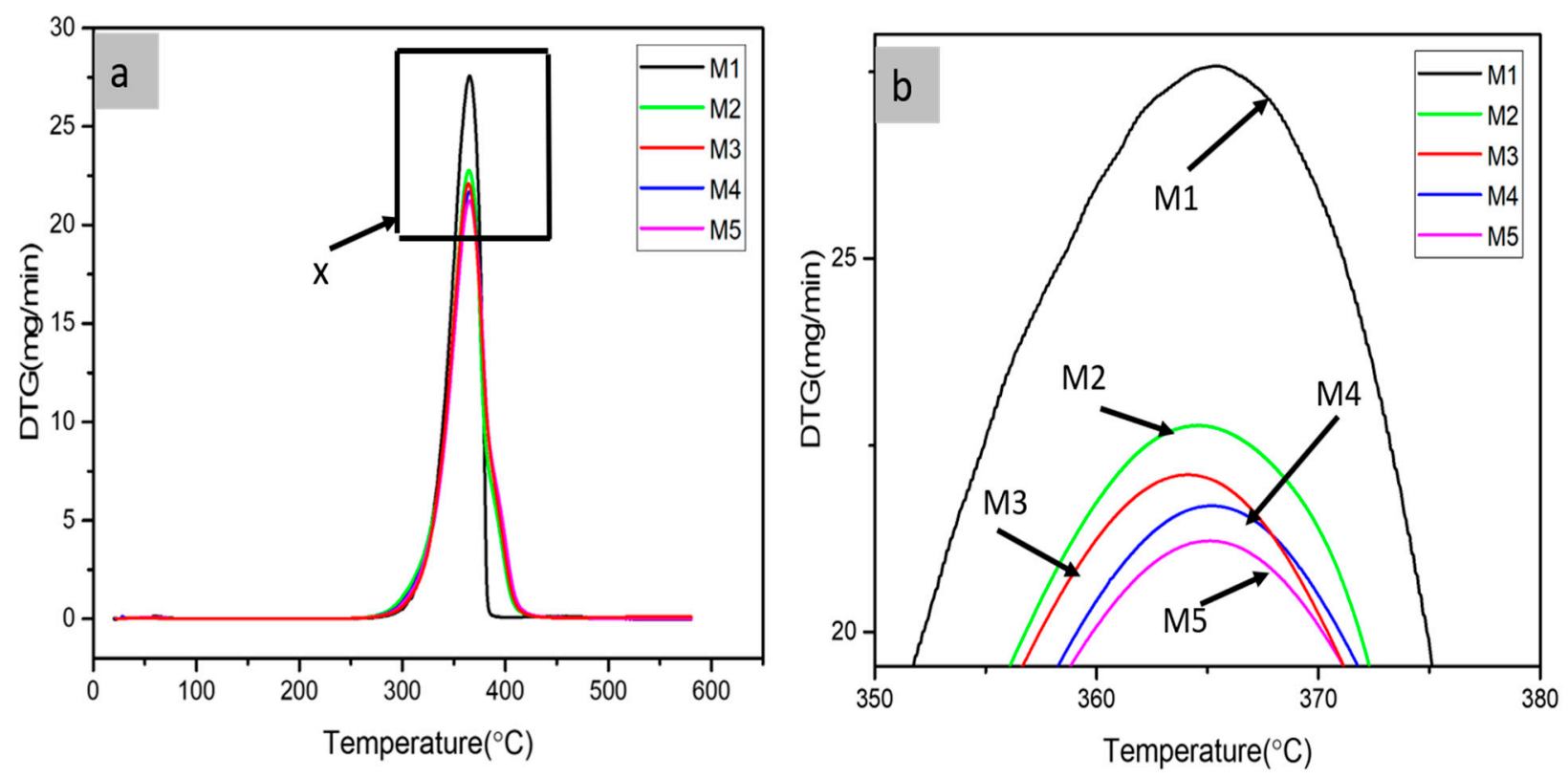

Figure 3. DTG of (a) PLA, PLA-PBS, PLA-PBS-MCC composite films, (b) zoomed x part.

DSC analysis characterizes the physical nature of the material. The DSC curves displayed two thermal transition temperatures: glass transition temperatures $\left(\mathrm{T}_{\mathrm{g}}\right)$, and the melting temperatures $\left(\mathrm{T}_{\mathrm{m}}\right)$ with the absence of crystallization $\left(\mathrm{T}_{\mathrm{c}}\right)$. The glass transition indicates a change of the degree of freedom of the molecules in the amorphous regions on increasing temperature in the polymer matrix [31]. Figure $4 a, b$ demonstrates the DSC thermograms behavior of the composite films.
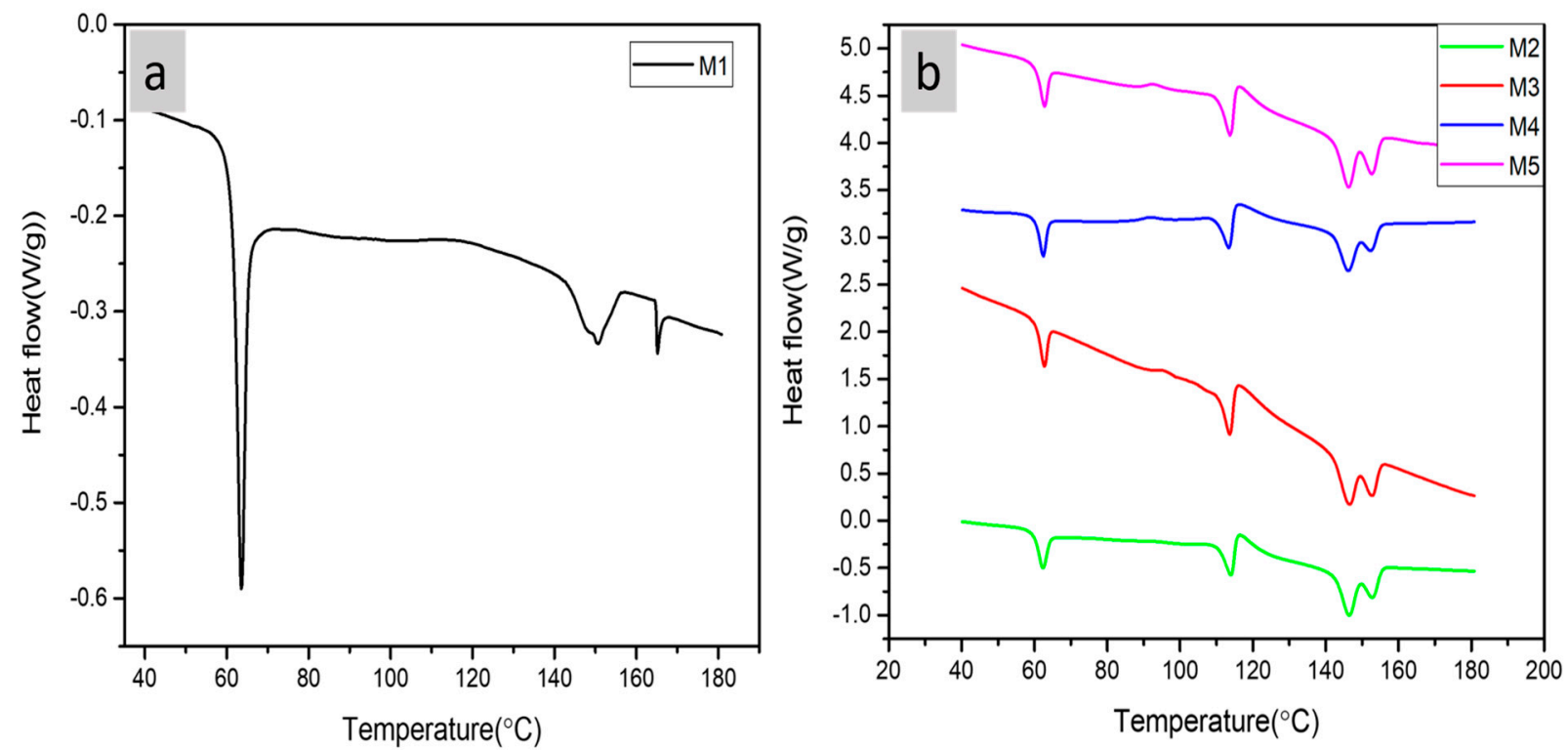

Figure 4. DSC of (a) PLA and (b) PLA-PBS, PLA-PBS-MCC composite films.

This endothermic peak values for PBS and MCC reinforced composites remain approximately contact however fluctuates to some degrees by the increase in MCC content. This endothermic peak indicates the disorder in the structure. The transition peak of PLA(M1) is obtained at 64 and on further addition of PBS and MCC in case of M2, M3, M4, and 
M4 the transition temperature reduces to $62{ }^{\circ} \mathrm{C}, 63^{\circ} \mathrm{C}, 63.10^{\circ} \mathrm{C}$ and $63.24^{\circ} \mathrm{C}$ respectively as mentioned in Table 4 . It reveals that the crystals in the pure PLA are more uniformly distributed as in the case of blend and also in the composites due to presence of other components during nucleation leads to crystallites varying in sizes and shapes [32]. This temperature is also relevant to the polymer's transition temperature from glassy state to a rubbery state, i.e., with characteristics such as hard and brittle to a flexible and soft material. The $\mathrm{T}_{\mathrm{g}}$ value increases with the addition of the MCC however it reduced with the addition of PBS alone in PLA composites. Also, the melting peak of PBS is obtained around $113^{\circ} \mathrm{C}$ in all the composites as shown in Table 4. As per some studies PBS does not induce the crystallization [33] or improve the crystalline nature of PLA [33,34]. The impeding effect of PBS on the crystallinity of PLA was observed during isothermal crystallization around the temperature of $60^{\circ} \mathrm{C}$, indicating that PBS hinders the rate of crystallization of PLA [35]. From Figure 4a neat PLA showed two melting endothermic peaks at $151{ }^{\circ} \mathrm{C}$ and $165.14{ }^{\circ} \mathrm{C}$. As evident from the Figure 4, the composites, M2, M3, M4, and M5 also exhibited two separate melting temperature peaks at approximately $146^{\circ} \mathrm{C}$ and $153^{\circ} \mathrm{C}$ as evident from Table 4 [36].

Table 4. DSC results of PLA, PLA-PBS, PLA-PBS-MCC composites.

\begin{tabular}{cccccccc}
\hline Sample & $\begin{array}{c}\mathbf{T}_{\mathbf{g}} \\
\left({ }^{\circ} \mathbf{C}\right)\end{array}$ & $\begin{array}{c}\mathbf{T}_{\mathbf{m}} \\
\left({ }^{\circ} \mathbf{C}\right)\end{array}$ & $\begin{array}{c}\Delta \mathbf{H} \\
\mathbf{( J / g})\end{array}$ & $\begin{array}{c}\mathbf{T}_{\mathbf{m} 1} \\
\left({ }^{\circ} \mathbf{C}\right)\end{array}$ & $\begin{array}{c}\Delta \mathbf{H} \\
(\mathbf{J} / \mathbf{g})\end{array}$ & $\begin{array}{c}\mathbf{T}_{\mathbf{m} 2} \\
\left({ }^{\circ} \mathbf{C}\right)\end{array}$ & $\begin{array}{c}\Delta \mathbf{H} \\
(\mathbf{J} / \mathbf{g})\end{array}$ \\
\hline M1 & 64 & - & - & 151 & 2.81 & 165.14 & 0.32 \\
M2 & 62 & 113.94 & 6.47 & 146.21 & 6.58 & 152.89 & 4.28 \\
M3 & 63 & 113.60 & 10.68 & 146.23 & 6.74 & 152.73 & 5.29 \\
M4 & 63.10 & 113.51 & 10.62 & 146.33 & 7.77 & 152.84 & 2.41 \\
M5 & 63.24 & 113.56 & 9.34 & 146.01 & 8.27 & 152.68 & 5.61 \\
\hline
\end{tabular}

\subsection{X-ray Diffractometry (XRD)}

The crystalline structures of PLA, PLA-PBS, and PLA-PBS-MCC composite were examined by XRD in order to examine the influence of varying content of MCC on the crystallinity of the PLA matrix. The XRD patterns in $2 \theta$ range of $20-30^{\circ}$ are evident from Figure 5. The pure PLA and PLA in the compositions displayed wide and indistinct diffraction patterns [37,38], indicating the existence of PLA in amorphous state mostly with small number of crystallites [38]. This may be due to lower rate of crystallization of PLA as a result faster cooling rates during processing $[39,40]$. Adding the PBS in the PLA resulted into small increment in the peak intensities and also in the crystalline nature of composite blends. Moreover, there was an insignificant co-crystallization among PLA and PBS [41] as also evident from DSC curve in Figure 4. Thus, PLA in the blends was not crystallized as indicated by the absence of PLA diffraction peak in all the four composites (M2, M3, M4, and M5), whereas the diffraction peak of PBS at $22.5^{\circ}$ is present in all PLA/PBS composites that increases with increase in MCC content. This can be attributed to the diffraction peaks of both PBS and MCC $\left(2 \theta=22.6^{\circ}\right)$ that overlap [42]. 


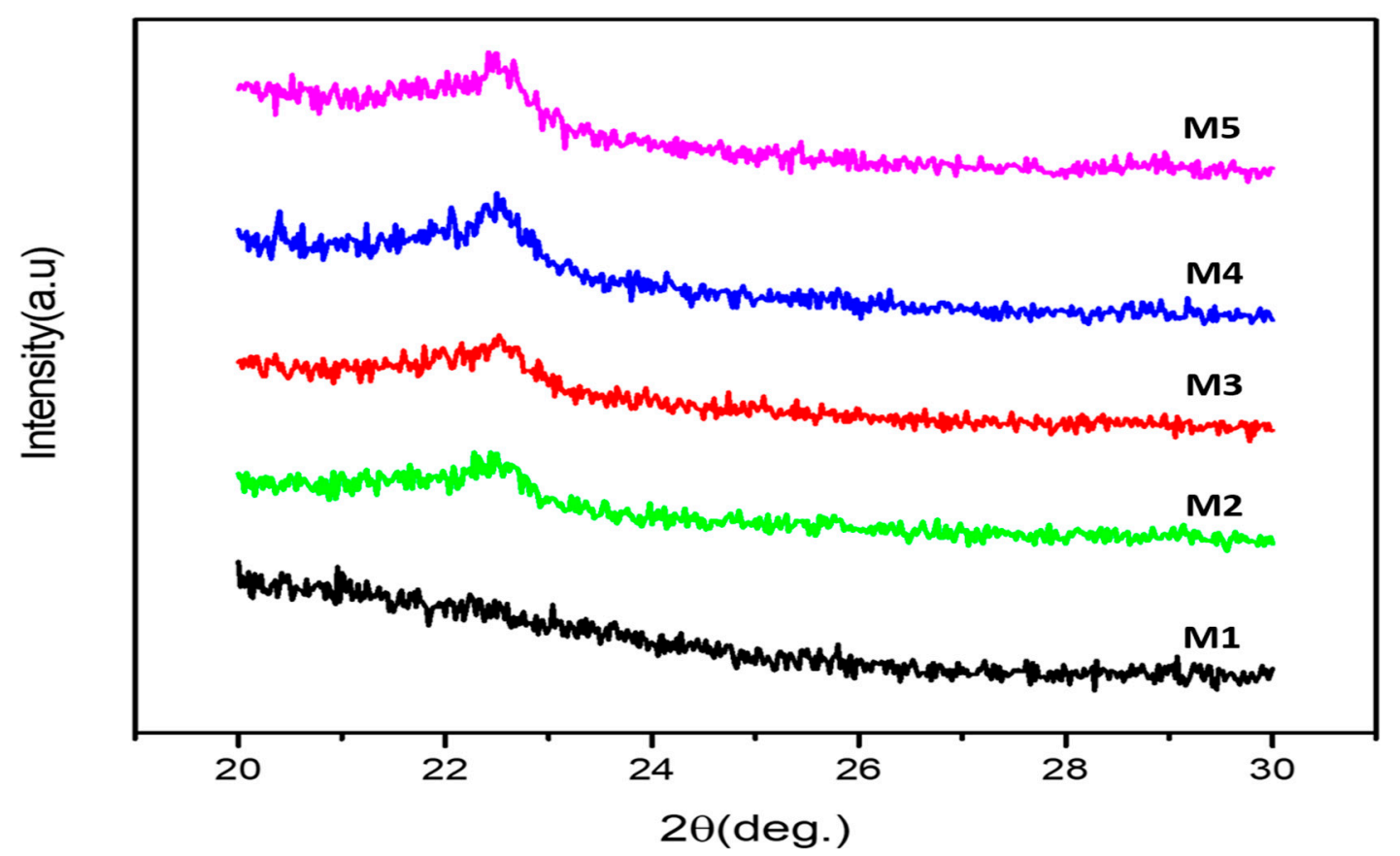

Figure 5. XRD of PLA, PLA-PBS, and PLA-PBS-MCC composite films.

\subsection{Fourier Transform Infrared Spectra (FTIR)}

FTIR spectra were analyzed to study the chemical structures of composites. The FTIR spectrum of PLA(M1), PLA-PBS(M2), PLA-PBS-MCC (M3, M4, and M5) (Figure 6) displayed characteristic peak at $3750 \mathrm{~cm}^{-1}$ (OH stretching vibration) $[43,44]$, and the peak intensity increases with increase in MCC content. The infrared spectra at 2993 represents the stretching vibrations of $\mathrm{CH}_{3}$ (asymmetric), and $2925 \mathrm{~cm}^{-1}$ showed the presence of stretching vibrations of $\mathrm{CH}_{3}$ (symmetric), respectively in case of PLA and then slowly disappears while as only $2946 \mathrm{~cm}^{-1}$ (symmetric stretching vibration of $\mathrm{CH}_{3}$ ) peak [44,45], was observed in PLA-PBS and PLA-PBS-MCC (M3, M4, and M5) composites becoming sharper with MCC content. The wide and strong absorption peak at $1753 \mathrm{~cm}^{-1}$ can be associated to the presence of $\mathrm{C}=\mathrm{O}$ stretching of the ester group with the addition of $\mathrm{PBS}$ were partially dispersed [29] and it broadens with addition of PBS as well as MCC, while as $1453 \mathrm{~cm}^{-1}$ represents bending vibration of $\mathrm{CH}_{3}$ (asymmetric) in all composites and the asymmetric $\mathrm{C}-\mathrm{O}-\mathrm{C}$ stretching mode at 1184; 1090; and $1047 \mathrm{~cm}^{-1}$ [39]. The vibration characteristic of the helical backbone with rocking mode of $\mathrm{CH} 3$ was observed at $956.2 \mathrm{~cm}^{-1}$ only in case of composites (M2, M3, M4, and M5). The two bands at 869 and $754 \mathrm{~cm}^{-1}$ presented the crystalline and amorphous phases of PLA in all compositions. The peak at $869 \mathrm{~cm}^{-1}$ could be represents the amorphous phase [46] and the peak at $754 \mathrm{~cm}^{-1}$ denotes the crystalline phase [47]. Overall, the peaks (band position) in the spectrum of PLA-PBS blend changed significantly as compared to PLA-PBS-MCC with no significant change, indicating there was no specific chemical reactions between the polymers and MCC. The curves of PLA-PBS-MCC, as shown in Figure 6, were same as that of pure PLA composite. These results show well agreement with the FESEM analysis. 


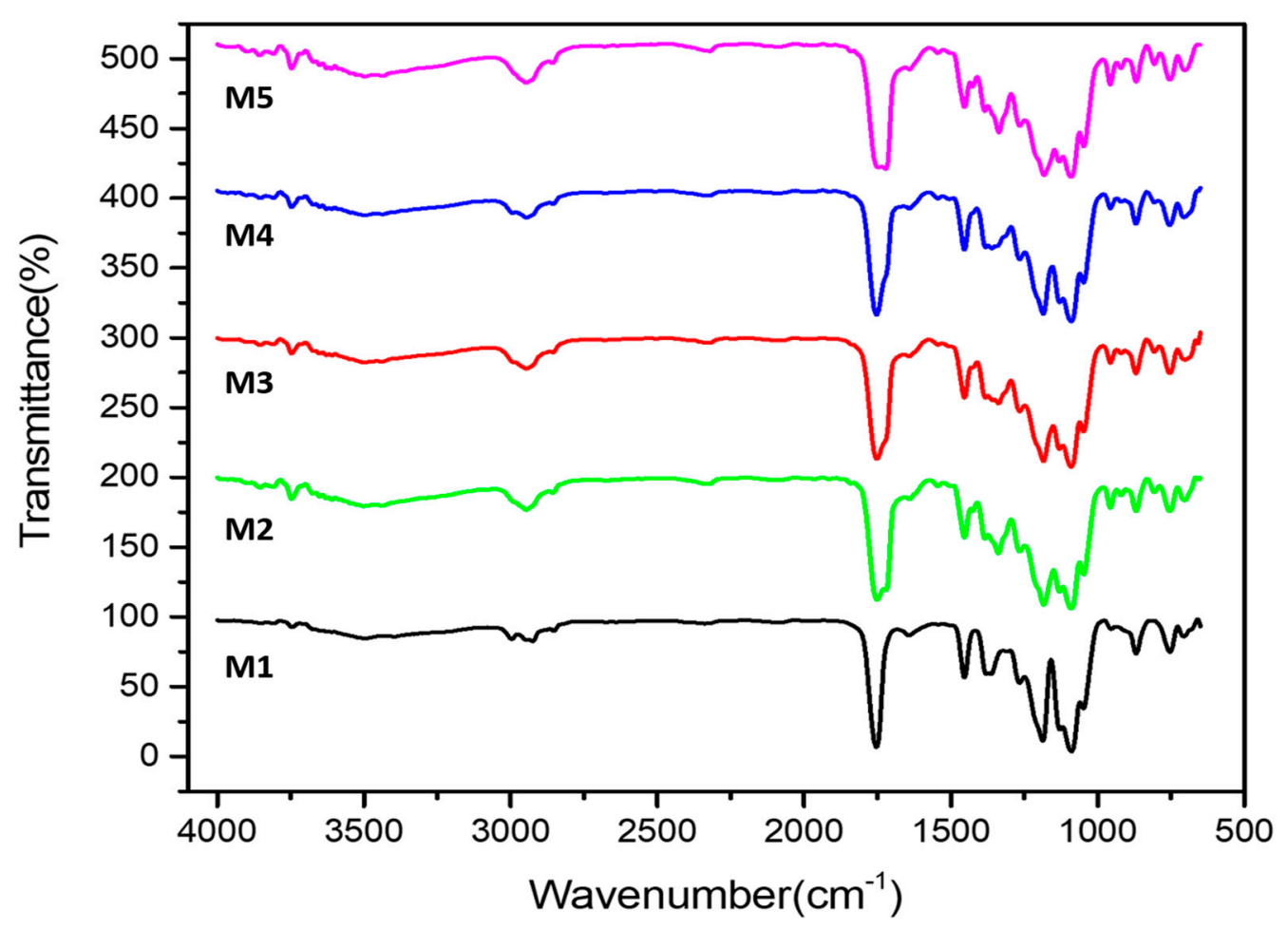

Figure 6. FTIR of PLA, PLA-PBS, and PLA-PBS-MCC composite films.

\subsection{Tensile Properties}

The tensile strength and tensile modulus of PLA(M1), PLA/PBS(M2), PLA/PBS/MCC (M3, M4, and M5) composites with different MCC content are demonstrated by Figure 7a,b respectively. The tensile strength and the tensile modulus of these composite films decreased on addition of PBS and decreased initially on addition of $0.5 \mathrm{wt} \%$ of MCC beyond that it further increases This is due to lower tensile strength and tensile modulus of PBS than PLA. The reduced values of tensile strength may also be attributed to the weak interactions at the interfaces of PLA and PBS, resulting into the inadequate transfer of stress across each polymer phase thereby leading to quicker fracture during the tensile deformation when compared to pure PLA. Also, there was a reduction in brittleness of PLA due to decreased values of modulus from 8500 to $5400 \mathrm{MPa}$ [48]. The decreased value of tensile strength at lower MCC content can be associated with the weak interactions at the interfaces of PLA-PBS matrix and MCC however it increased at higher contents of MCC due to their binding ability. The binder functionality of MCC depends upon its ability to deform plastically on application of compressive force. MCC particles form hydrogen bonds leading to strong compacts and their critical properties corresponding to their functionality as a binder include particle size, moisture content, bulk density, specific surface area, and crystallinity [49]. Similar results of decreased tensile strength were obtained by Ochi [50] in their studies. The increase in tensile strength with higher content of MCC addition in PLA-PBS matrix can be attributed to the interface action of MCC and the penetration of PLA into the network and better interaction between MCC and PLA resin as evident from FESEM images in Figure 1c-e. The increasing of the tensile modulus on addition of MCC beyond $1 \mathrm{wt} \%$ might be due to the rigid MCC that enhances stiffness of the PLA composites by restricting the molecular movement and the distortion of PLA chains. Luz et al. [51] revealed that insertion of the fibers can increase tensile modulus due to higher modulus of fibers as compared to the modulus of thermoplastics. 

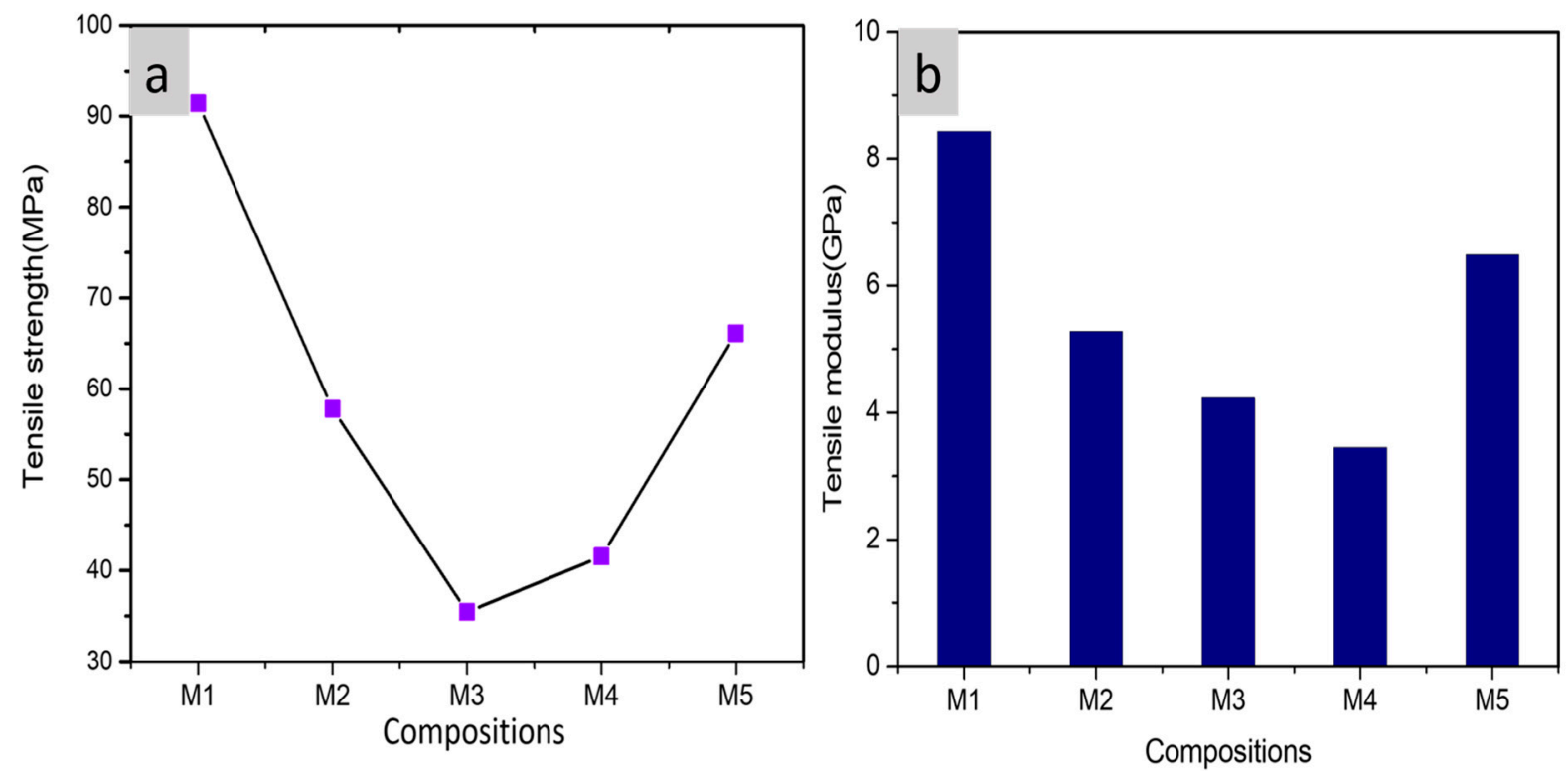

Figure 7. (a) Tensile strength (MPa), (b) tensile modulus (GPa), of PLA, PLA-PBS, and PLA-PBS-MCC composite films.

The elongation at break of the composites is presented in Figure 8. It reveals that the elongation at break increases on addition of PBS and further decreases with addition of MCC insignificantly. This effect is due to the high flexibility of PBS within the PLA matrix resulting into decrease in the brittleness of the blends [52]. However, MCC inclusion reduces elongation at break but have values greater than pure PLA. Similar effect of MCC extracted from cotton waste on the PLA-PBS blend was reported by Chaiwutthinan et al. [42]. Overall, the elongation at break of the PLA composite films improves.

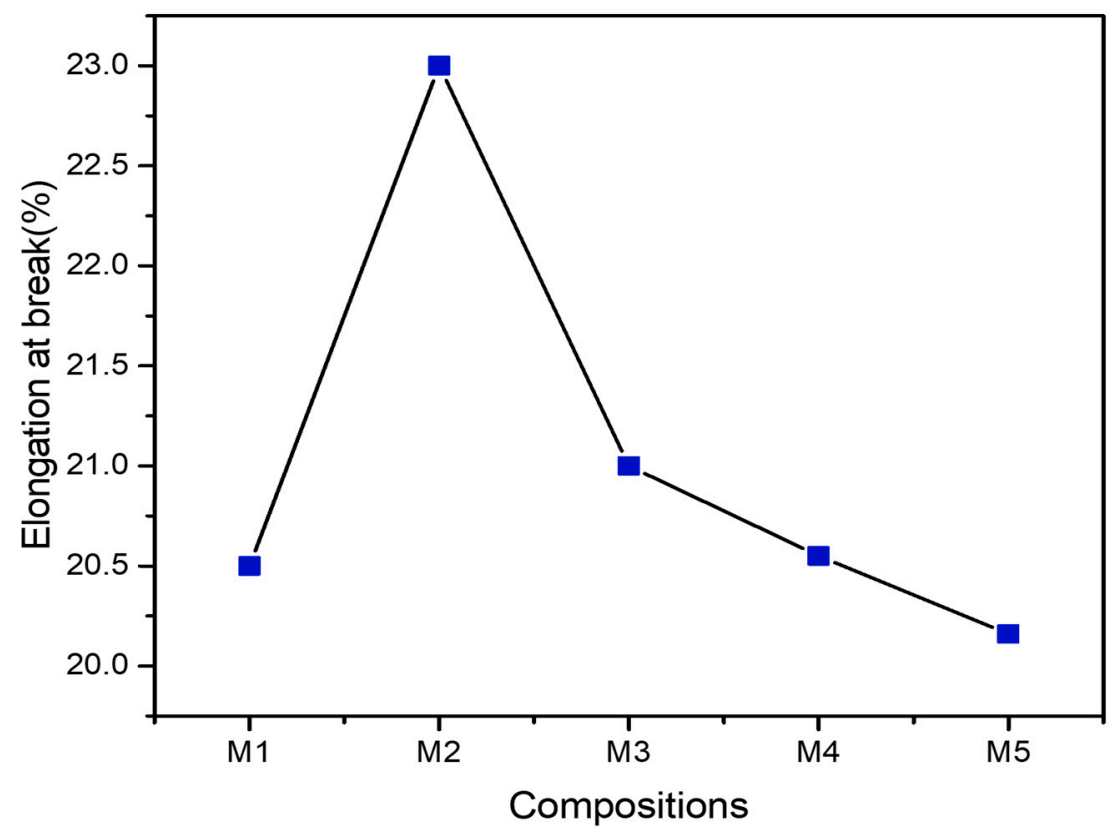

Figure 8. Elongation at $\operatorname{break}(\mathrm{mm})$ of PLA, PLA-PBS, and PLA-PBS-MCC composite films

\subsection{SEM Analysis of Fractured Surfaces}

The tensile properties of the composites also depend upon the compatibility of PLA with PBS and MCC, they also depend on the behavior of composites when loaded. We studied the microstructures of fractured surfaces of the composites as shown in Figure 9. The microstructure indicated the dispersion and compatibility in the composites. SEM 
morphology of the surfaces(fractured) during tensile testing of the pure PLA as shown in Figure 9a exhibited a clear even-fractured surface and thus showed a nature of brittle material, whereas the fractured surfaces of PLA-PBS blends are rougher as evident from Figure $9 \mathrm{~b}-\mathrm{e}$, suggesting more flexibility of the samples. This can be due to presence of PBS with higher toughness. The interfaces between PLA and PBS in all the blends were clear as observed in Figure 9. This reveals the immiscibility of the blend [53]. Moreover, the blends with relatively low MCC contents exhibited more interfacial debonding as a result some PBS particles are get removed completely from the composites during the fracture process as evident from Figure 9b-e. In addition, PBS particles in the composites without MCC, exhibited non-uniform distribution within PLA matrix, and thus the gaps present at the interface of PLA and PBS can enhanced water penetration by forming permeation channels that can further facilitate the hydrolytic degradation [54].

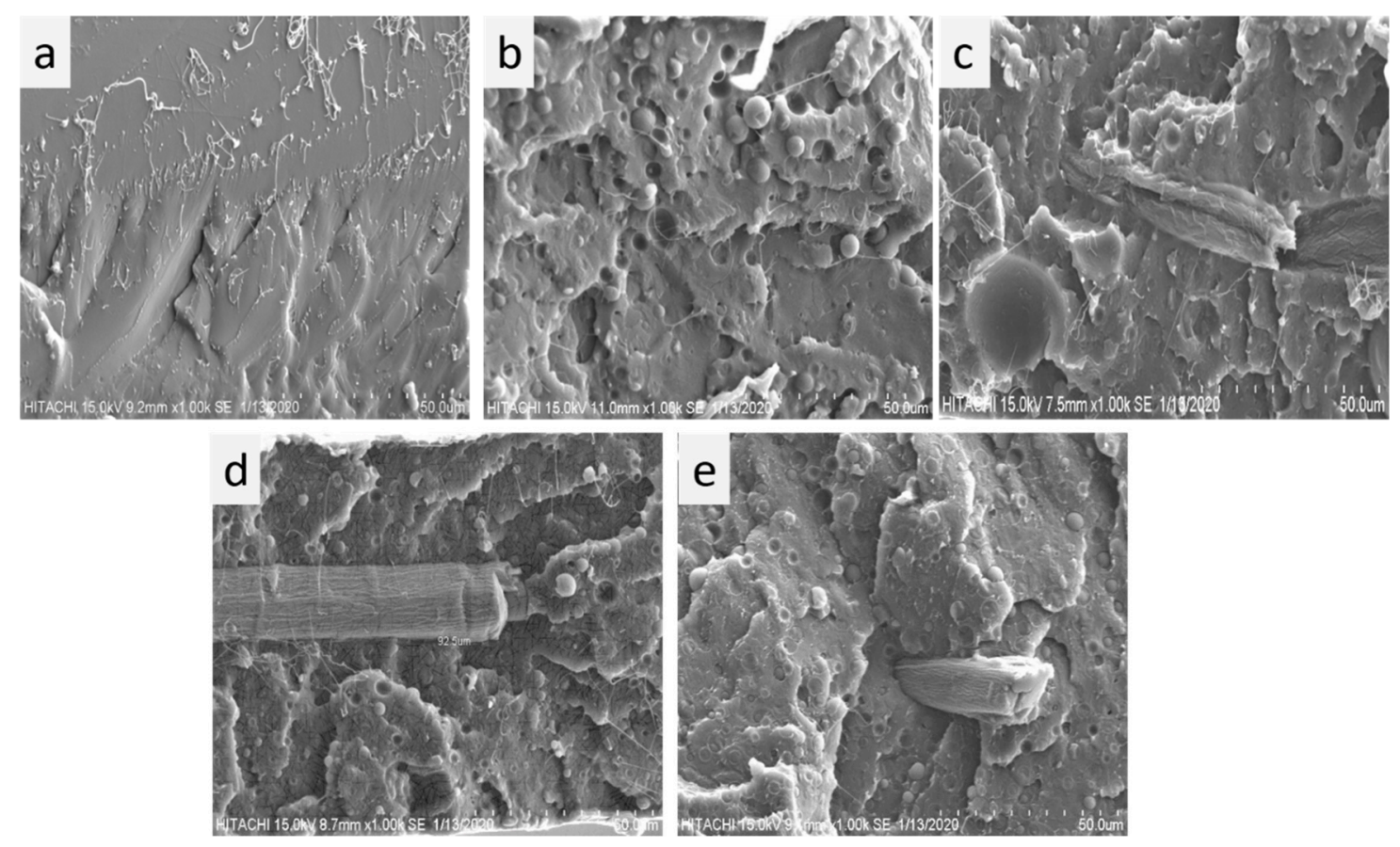

Figure 9. SEM morphology of the fractured surfaces of composite films: (a) M1, (b) M2, (c) M3, (d) M4, (e) M5.

As evident from Figure 9c, the PLA-PBS-MCC cross section with $0.5 \mathrm{wt} \% \mathrm{MCC}$ in the PLA-PBS matrix show the rod like structure of MCC was pulled out due to fracturing of the composite leaving a hole on the surface. These exposed MCC rods also indicate poor bonding interface thus reason of deterioration in performance of the composite. The PLA-PBS composite films with MCC exhibited a better compatibility of PLA with PBS in comparison to the composite films without MCC as evident from Figure 9b-e. However, there are MCC pulled outs that are clearly visible. On addition of more MCC (above $0.5 \mathrm{wt} \%$ ), the MCC rods showed a well-defined and sharp edge as evident from Figure $9 \mathrm{~d}$,e. Also, PLA-PBS-MCC composites with MCC content more than $0.5 \mathrm{wt} \%$ the cross-sectional surface consists of least number of voids in comparison to composites with lower MCC content. Moreover, observed relatively compact and smooth cross-sectional surface for M4 and M5 as evident from Figure 9d,e. Therefore, there was increase in binding force of the composites on increasing concentration of MCC indicating that MCC modified the surface successfully resulting into enhanced interfacial tension [45]. On addition of $1.5 \mathrm{wt} \%$ of MCC, an additional fractured rod-shaped MCC were observed (Figure 9e); indicating the improvement in the cohesive forces at the interface of MCC and the PLA matrix; thus the matrix interface became more miscible as a result increases the compatibility of PLA with 
PBS. Thus, the incorporation of MCC improvises the interfacial complications between PLA, PBS, and MCC thereby improving mechanical properties of the composites.

\section{Conclusions}

In this research work, PLA, PLA-PBS, and PLA-PBS-MCC $(0.5,1$, and $1.5 \mathrm{wt} \%)$ composites, where MCC extracted from bamboo fiber, were successfully prepared by hot pressing technique. Although PBS revealed insignificant impact on PLA's crystallinity and mechanical properties however it changed PLA from brittle to flexible material that was further enhanced by the addition of MCC. In addition, MCC improved the interfacial bonding between PLA and PBS in the composites. Furthermore, MCC enhanced the crystallinity, thermal stability as well as the tensile strength of the PLA-PBS blends. The tensile strength and tensile modulus of PLA-PBS and PLA-PBS-MCC were lower at low MCC content when compared with the pure PLA composites however the elongation at break of PLA-PBS and PLA-PBS-MCC was found to be higher than that of PLA. The SEM analysis of surfaces (fractured) reveal the better bonding of MCCs in the composites containing MCC and thus exhibit better mechanical properties. Thus, the PBS and MCC-reinforced PLA matrix composites can be regarded as a potential material for packaging applications.

Author Contributions: Conceptualization, M.R., M.J., and A.H.B.; Methodology, M.R. and M.J.; Validation, M.J., A.H.B., and S.A.; Formal analysis and investigation, M.R. and B.P.; Writing-original draft preparation, M.R.; Writing—review and editing, M.J., S.A., B.P., and A.H.B.; Supervision and project administration, M.J.; Funding acquisition, M.J. All authors have read and agreed to the published version of the manuscript.

Funding: The authors are grateful to Malaysian Industry-Government Group for High Technology (MIGHT) for Financial support of this work under Newton-Ungku Omar Fund (grant no. 6300873). The authors would like to extend their gratitude to King Saud University (Riyadh, Saudi Arabia) for the funding of this research through Researchers Supporting Project number (RSP-2020/241).

Informed Consent Statement: Not applicable.

Data Availability Statement: Not applicable.

Conflicts of Interest: The authors declare no conflict of interest.

\section{References}

1. Fang, Q.; Hanna, M.A. Rheological properties of amorphous and semicrystalline polylactic acid polymers. Ind. Crop. Prod. 1999, 10, 47-53. [CrossRef]

2. Ogata, N.; Jimenez, G.; Kawai, H.; Ogihara, T. Structure and thermal/mechanical properties of poly(l-lactide)-clay blend. J. Polym. Sci. Part B Polym. Phys. 1997, 35, 389-396. [CrossRef]

3. Armentano, I.; Fortunati, E.; Burgos, N.; Dominici, F.; Luzi, F.; Fiori, S.; Jiménez, A.; Yoon, K.; Ahn, J.; Kang, S.; et al. Processing and characterization of plasticized PLA/PHB blends for biodegradable multiphase systems. Express Polym. Lett. 2015, 9, 583-596. [CrossRef]

4. Bai, H.; Huang, C.; Xiu, H.; Gao, Y.; Zhang, Q.; Fu, Q. Toughening of poly(l-lactide) with poly( $\varepsilon$-caprolactone): Combined effects of matrix crystallization and impact modifier particle size. Polymer 2013, 54, 5257-5266. [CrossRef]

5. Mittal, V.; Akhtar, T.; Matsko, N. Mechanical, Thermal, Rheological and Morphological Properties of Binary and Ternary Blends of PLA, TPS and PCL. Macromol. Mater. Eng. 2015, 300, 423-435. [CrossRef]

6. Bhatia, A.; Gupta, R.K.; Bhattacharya, S.N.; Choi, H.J. Compatibility of biodegradable poly (lactic acid) (PLA) and poly (butylene succinate) (PBS) blends for packaging application. Korea Aust. Rheol. J. 2007, 19, 125-131.

7. Liu, X.; Dever, M.; Fair, N.; Polymer, R.B.-J.U. Thermal and Nechanical Properties of Poly (Lactic Acid) and Poly (Ethylene/Butylene Succinate) Blends; Springer: Berlin, Germany, 1997; Volume 5, pp. 225-235.

8. Yokohara, T.; Yamaguchi, M. Structure and properties for biomass-based polyester blends of PLA and PBS. Eur. Polym. J. 2008, 44, 677-685. [CrossRef]

9. Homklin, R.; Hongsriphan, N. Mechanical and Thermal Properties of PLA/PBS Co-continuous Blends Adding Nucleating Agent. Energy Procedia 2013, 34, 871-879. [CrossRef]

10. Lin, N.; Huang, J.; Chang, P.R.; Feng, J.; Yu, J. Surface acetylation of cellulose nanocrystal and its reinforcing function in poly(lactic acid). Carbohydr. Polym. 2011, 83, 1834-1842. [CrossRef] 
11. Lu, T.; Liu, S.; Jiang, M.; Xu, X.; Wang, Y.; Gou, J.; Hui, D.; Chen, X. Effects of modifications of bamboo cellulose fibers on the improved mechanical properties of cellulose reinforced poly(lactic acid) composites. Compos. Part B Eng. 2014, 62, 191-197. [CrossRef]

12. Haldar, D.; Purkait, M. Micro and nanocrystalline cellulose derivatives of lignocellulosic biomass: A review on synthesis, applications and advancements. Carbohydr. Polym. 2020, 250. [CrossRef] [PubMed]

13. Das, K.; Ray, D.; Bandyopadhyay, N.R.; Sengupta, S. Study of the Properties of Microcrystalline Cellulose Particles from Different Renewable Resources by XRD, FTIR, Nanoindentation, TGA and SEM. J. Polym. Environ. 2010, 18, 355-363. [CrossRef]

14. Elsakhawy, M.; Hassan, M. Physical and mechanical properties of microcrystalline cellulose prepared from agricultural residues. Carbohydr. Polym. 2007, 67, 1-10. [CrossRef]

15. Jahan, M.S.; Saeed, A.; He, Z.; Ni, Y. Jute as raw material for the preparation of microcrystalline cellulose. Cellular 2010, 18, 451-459. [CrossRef]

16. Courgneau, C.; Domenek, S.; Guinault, A.; Avérous, L.; Ducruet, V. Analysis of the Structure-Properties Relationships of Different Multiphase Systems Based on Plasticized Poly(Lactic Acid). J. Polym. Environ. 2011, 19, 362-371. [CrossRef]

17. Shih, Y.-F.; Wang, T.Y.; Jeng, R.J.; Wu, J.Y.; Teng, C.C. Biodegradable nanocomposites based on poly(butylene succinate)/organoclay. J. Polym. Environ. 2007, 15, 151-158. [CrossRef]

18. Zhou, J.; Wang, X.; Hua, K.; Duan, C.; Zhang, W.; Ji, J.-H.; Yang, X. Enhanced mechanical properties and degradability of poly(butylene succinate) and poly(lactic acid) blends. Iran. Polym. J. 2013, 22, 267-275. [CrossRef]

19. Rico, M.; Rodríguez-Llamazares, S.; Barral, L.; Bouza, R.; Montero, B. Processing and characterization of polyols plasticized-starch reinforced with microcrystalline cellulose. Carbohydr. Polym. 2016, 149, 83-93. [CrossRef]

20. Liu, Y.; Li, Y.; Chen, H.M.; Yang, G.; Zheng, X.; Zhou, S. Water-induced shape-memory poly(d,l-lactide)/microcrystalline cellulose composites. Carbohydr. Polym. 2014, 104, 101-108. [CrossRef]

21. Cao, Z.; Lu, Y.; Zhang, C.; Zhang, Q.; Zhou, A.; Hu, Y.; Wu, D.; Tao, G.; Gong, F.; Ma, W.; et al. Effects of the chain-extender content on the structure and performance of poly(lactic acid)-poly(butylene succinate)-microcrystalline cellulose composites. $J$. Appl. Polym. Sci. 2017, 134, 1-8. [CrossRef]

22. Amado, C.M.; Minahk, C.J.; Cilli, E.; Oliveira, R.G.; Dupuy, F.G. Bacteriocin enterocin CRL35 is a modular peptide that induces non-bilayer states in bacterial model membranes. Biochim. Biophys. Acta (BBA) Biomembr. 2020, 1862. [CrossRef]

23. Rasheed, M.; Jawaid, M.; Karim, Z.; Abdullah, L.C. Morphological, Physiochemical and Thermal Properties of Microcrystalline Cellulose (MCC) Extracted from Bamboo Fiber. Molecules 2020, 25, 2824. [CrossRef] [PubMed]

24. Jiang, L.; Zhang, J.; Wolcott, M.P. Comparison of polylactide/nano-sized calcium carbonate and polylactide/montmorillonite composites: Reinforcing effects and toughening mechanisms. Polymer 2007, 48, 7632-7644. [CrossRef]

25. Hassan, E.A.; Elarabi, S.E.; Wei, Y.; Yu, M. Biodegradable poly (lactic acid)/poly (butylene succinate) fibers with high elongation for health care products. Text. Res. J. 2017, 88, 1735-1744. [CrossRef]

26. Thiangtham, S.; Runt, J.; Saito, N.; Manuspiya, H. Fabrication of biocomposite membrane with microcrystalline cellulose (MCC) extracted from sugarcane bagasse by phase inversion method. Cellular 2019, 27, 1367-1384. [CrossRef]

27. Luzi, F.; Fortunati, E.; Jiménez, A.; Puglia, D.; Pezzolla, D.; Gigliotti, G.; Kenny, J.M.; Chiralt, A.; Torre, L. Production and characterization of PLA_PBS biodegradable blends reinforced with cellulose nanocrystals extracted from hemp fibres. Ind. Crop. Prod. 2016, 93, 276-289. [CrossRef]

28. Zhang, X.; Shi, J.; Ye, H.-M.; Dong, Y.; Zhou, Q. Combined effect of cellulose nanocrystals and poly(butylene succinate) on poly(lactic acid) crystallization: The role of interfacial affinity. Carbohydr. Polym. 2018, 179, 79-85. [CrossRef]

29. Chaiwutthinan, P.; Pimpan, V.; Chuayjuljit, S.; Leejarkpai, T. Biodegradable Plastics Prepared from Poly(lactic acid), Poly(butylene succinate) and Microcrystalline Cellulose Extracted from Waste-Cotton Fabric with a Chain Extender. J. Polym. Environ. 2015, 23, 114-125. [CrossRef]

30. Xiuju, Z.; Juncai, S.; Huajun, Y.; Zhidan, L.; Shaozao, T. Mechanical Properties, Morphology, Thermal Performance, Crystallization Behavior, and Kinetics of PP/Microcrystal Cellulose Composites Compatibilized by Two Different Compatibilizers. J. Thermoplast. Compos. Mater. 2011, 24, 735-754. [CrossRef]

31. Baskaran, R.; Selvasekarapandian, S.; Kuwata, N.; Kawamura, J.; Hattori, T. Conductivity and thermal studies of blend polymer electrolytes based on PVAc-PMMA. Solid State Ionics 2006, 177, 2679-2682. [CrossRef]

32. Mandal, A.; Chakrabarty, D. Studies on the mechanical, thermal, morphological and barrier properties of nanocomposites based on poly(vinyl alcohol) and nanocellulose from sugarcane bagasse. J. Ind. Eng. Chem. 2014, 20, 462-473. [CrossRef]

33. Robeson, L.M. Fundamentals of Polymer Blends. Polym. Blends 2007, 11-64. [CrossRef]

34. Diani, J.; Gall, K. Toughening modification of PLLA/PBS blendsviai in situ compatibilization. Polym. Eng. Sci. 2009, 26-33. [CrossRef]

35. Ji, D.; Liu, Z.; Lan, X.; Wu, F.; Xie, B.; Yang, M. Morphology, rheology, crystallization behavior, and mechanical properties of poly(lactic acid)/poly(butylene succinate)/dicumyl peroxide reactive blends. J. Appl. Polym. Sci. 2013, 131, 1-8. [CrossRef]

36. Silverajah, V.S.G.; Ibrahim, N.A.; Yunus, W.M.Z.W.; Abu Hassan, H.; Woei, C.B. A Comparative Study on the Mechanical, Thermal and Morphological Characterization of Poly(lactic acid)/Epoxidized Palm Oil Blend. Int. J. Mol. Sci. 2012, 13, 5878-5898. [CrossRef]

37. Li, L.; Song, G.; Tang, G. Novel Biodegradable Polylactide/Poly(butylene succinate) Composites via Cross-Linking with Methylene Diphenyl Diisocyanate. Polym. Technol. Eng. 2013, 52, 1183-1187. [CrossRef] 
38. Yeh, J.; Tsou, C.-H.; Li, Y.-M.; Xiao, H.-W.; Wu, C.-S.; Chai, W.-L.; Lai, Y.-C.; Wang, C.-K. The compatible and mechanical properties of biodegradable poly(Lactic Acid)/ethylene glycidyl methacrylate copolymer blends. J. Polym. Res. 2012, 19. [CrossRef]

39. Zheng, M.; Luo, X. Phase Structure and Properties of Toughened Poly(L-Lactic Acid)/Glycidyl Methacrylate Grafted Poly(Ethylene Octane) Blends Adjusted by the Stereocomplex. Polym. Technol. Eng. 2013, 52, 1250-1258. [CrossRef]

40. Zou, H.; Yi, C.; Wang, L.; Xu, W. Crystallization, hydrolytic degradation, and mechanical properties of poly (trimethylene terephthalate)/poly(lactic acid) blends. Polym. Bull. 2009, 64, 471-481. [CrossRef]

41. Park, J.W.; Im, S.S. Phase behavior and morphology in blends of poly(L-lactic acid) and poly(butylene succinate). J. Appl. Polym. Sci. 2002, 86, 647-655. [CrossRef]

42. Chaiwutthinan, P.; Song, Z.H.; Leejarkpai, T.; Chuayjuljit, S. Use of Microcrystalline Cellulose Prepared from Cotton Fabric Waste to Prepare Poly(butylene succinate) Composites. Adv. Mater. Res. 2011, 356-360, 430-434. [CrossRef]

43. Pamuła, E.; Błażewicz, M.; Paluszkiewicz, C.; Dobrzyński, P. FTIR study of degradation products of aliphatic polyesters-carbon fibres composites. J. Mol. Struct. 2001, 596, 69-75. [CrossRef]

44. Kemala, T.; Budianto, E.; Soegiyono, B. Preparation and characterization of microspheres based on blend of poly(lactic acid) and poly( $\epsilon$-caprolactone) with poly(vinyl alcohol) as emulsifier. Arab. J. Chem. 2012, 5, 103-108. [CrossRef]

45. Qu, P.; Gao, Y.; Wu, G.F.; Zhang, L.P. Nanocomposites of Poly(lactic acid) reinforced with cellulose nanofibrils. BioResources 2010, 5, 1811-1823. [CrossRef]

46. Garlotta, D. A Literature Review of Poly(Lactic Acid). J. Polym. Environ. 2001, 9, 63-84. [CrossRef]

47. Yang, Z.; Peng, H.; Wang, W.; Liu, T. Crystallization behavior of poly(E-caprolactone)/layered double hydroxide nanocomposites. J. Appl. Polym. Sci. 2010, 116, 2658-2667. [CrossRef]

48. Chaiwutthinan, P.; Leejarkpai, T.; Kashima, D.P.; Chuayjuljit, S. Poly(Lactic Acid)/Poly(Butylene Succinate) Blends Filled with Epoxy Functionalised Polymeric Chain Extender. Adv. Mater. Res. 2013, 664, 644-648. [CrossRef]

49. Thoorens, G.; Krier, F.; Leclercq, B.; Carlin, B.; Pestieau, A. Microcrystalline cellulose, a direct compression binder in a quality by design environment-A review. Int. J. Pharm. 2014, 473, 64-72. [CrossRef]

50. Ochi, S. Mechanical properties of kenaf fibers and kenaf/PLA composites. Mech. Mater. 2008, 40, 446-452. [CrossRef]

51. Luz, S.; Gonçalves, A.R.; Del'Arco, A. Mechanical behavior and microstructural analysis of sugarcane bagasse fibers reinforced polypropylene composites. Compos. Part A Appl. Sci. Manuf. 2007, 38, 1455-1461. [CrossRef]

52. Bhatia, A.; Gupta, R.K.; Bhattacharya, S.N.; Choi, H.J. Effect of Clay on Thermal, Mechanical and Gas Barrier Properties of Biodegradable Poly(lactic acid)/Poly(butylene succinate) (PLA/PBS) Nanocomposites. Int. Polym. Process. 2010, $25,5-14$. [CrossRef]

53. Shibata, M.; Inoue, Y.; Miyoshi, M. Mechanical properties, morphology, and crystallization behavior of blends of poly(l-lactide) with poly (butylene succinate-co-l-lactate) and poly (butylene succinate). Polymer 2006, 47, 3557-3564. [CrossRef]

54. Wang, Y.-P.; Xiao, Y.-J.; Duan, J.; Yang, J.-H.; Wang, Y.; Zhang, C.-L. Accelerated hydrolytic degradation of poly(lactic acid) achieved by adding poly(butylene succinate). Polym. Bull. 2015, 73, 1067-1083. [CrossRef] 